УДК [622.673.1: 681.514.54]

DOI: 10.31471/1993-9981-2018-2(41)-25-33

\title{
ОПТИМИЗАЦИЯ СТРУКТУРЫ МОБИЛЬНОЙ СИСТЕМЫ КОНТРОЛЯ
}

\author{
B.B. Лопатин \\ Институт геотехнической механики им. Н.С. Полякова Национальной академии наук Украины \\ ул. Симферопольская 2а, г. Днепр, 49005. тел. (0562) 46-01-51, факс (0562)46-24-26 \\ e-mailnanu@igtm.dp.ua
}

Гірські і нафтогазові підприємства України експлуатують потенційно небезпечне обладнання різних виробників знаходиться на межі вироблення ресурсу. Це вимагає створення методів і засобів технологічного контролю відповідає нормативно-правовим актам і галузевим стандартам. Найбільш перспективними засобами технологічного контролю в гірській і нафтогазовій галузях є мобільні системи контролю (МСК). Основне завдання МСК - оснащення споживачів, які обслуговують обладнання потенційно небезпечних виробництв, надійними компактними засобами неруйнівного контролю та моніторингу адаптованими до конкретного об'єкта. Які можуть виявити реакцію контрольованого об'єкта на зовнішні впливи, визначити обмеження і заборони, необхідні для нормального подальшого функціонування об'єкта контролю.

Як правило, апаратура МСК формується з серійних вимірювальних перетворювачів, пристроїв і датчиків, що диктується конкретним об'єктом в гірській або нафтогазовій галузях. Інформаційна і конструктивна сумісність в МСК досягається спеціальним інтерфейсом. Оптимізація і гнучке поєднання схем МСК в загальну структуру для різних початкових умов (структуризація) здійснюється зворотними зв'язками, які здійснюють взаємодію з іншими елементами і що роблять вплив на характер роботи МСК в цілому. Проаналізовано суперечності об'єднання структури МСК за допомогою математичного моделювання апріорної інформації. Розглянуто загальні та різнорідні складові в структурі МСК і вимірювальних засобів. Показані спільні та відмінні функції і операції, коли елементи апроксимації математичних моделей включені безпосередньо в контур МСК. Викладений матеріал дає чітке визначення МСК, іiї відмінні риси від відомих систем технологічного контролю, особливості їі дослідження та шляхи подолання проблем контролю властивостей і процесів при роботі гірничої або нафтогазового обладнання. Бібліогр. 15, рис.2

Ключові слова: мобільна система контролю (МСК), технологічний контроль, система реального часу (СРЧ), зворотний зв'язок, властивості, структурування, апроксимація, модифіковуваність, похибка, багатоваріантність, математична модель, протиріччя.

Mining and oil and gas enterprises of Ukraine exploit potentially dangerous equipment of various manufacturers located on the verge of resource development. This requires the creation of methods and means of technological control in accordance with regulatory and legal acts and industry standards. The most promising means of technological control in the mining and oil and gas industries are mobile control systems (MSC). The main task of the MSC is to equip consumers who service equipment of potentially hazardous industries with reliable compact nondestructive testing and monitoring tools adapted to a specific facility. Which can detect the reaction of the controlled object to external disturbing effects, determine the limitations and prohibitions necessary for the normal further operation of the monitoring object.

As a rule, MCS equipment is formed from serial measuring converters, devices and sensors, which is dictated by a specific object in the mining or oil and gas industries. Informational and constructive compatibility in MCS is achieved by a special interface. Optimization and flexible integration of MCS schemes into a common structure for different initial conditions (structuring) is carried out by feedbacks that interact with other elements and influence the nature of the work of MCS in general. The contradictions of combining the structure of MCSs through mathematical modeling of a priori information are analyzed. General and heterogeneous components in the structure of MSC and measuring instruments are considered. Shown are common and distinctive functions and operations, when elements of the approximation of mathematical models are included directly in the MSC contour. The material presented gives a clear definition of MCS, its distinctive features from known technological control systems, the features of its research and ways to overcome the problems of controlling properties and processes in the operation of mining or oil and gas equipment. Bibliogr. 15, Fig. 2

Keywords: mobile control system (MCS), technological control, real-time system (RTS), feedback, properties, structuring, approximation, tunability, error, multivariance, mathematical model, contradiction. 
Горные и нефтегазовые предприятия Украины эксплуатируют потенциально опасное оборудование различных производителей находящееся на грани выработки ресурса. Это требует создание методов и средств технологического контроля отвечающим нормативно-правовым актам и отраслевым стандартам. Наиболее перспективными средствами технологического контроля в горной и нефтегазовой отраслях являются мобильные системы контроля (МСК). Основная задача МСК - оснащение потребителей, обслуживающих оборудование потенциально опасных производств, надежными компактными средствами неразрушающего контроля и мониторинга адаптированными к конкретному объекту. Которые могут выявить реакцию контролируемого объекта на внешние возмущающие воздействия, определить ограничения и запреты, необходимые для нормального дальнейшего функционирования объекта контроля.

Как правило, аппаратура МСК формируется из серийных измерительных преобразователей, устройств и датчиков, что диктуется конкретным объектом в горной или нефтегазовой отраслях. Информационная и конструктивная совместимость в МСК достигается специальным интерфейсом. Оптимизация и гибкое объединение схем МСК в общую структуру для различных начальных условий (структуризация) осуществляется обратными связями, осуществляющими взаимодействие с другими элементами и оказывающими влияние на характер работы МСК в целом. Проанализированы противоречия объединения структуры МСК посредством математического моделирования априорной информации. Рассмотрены общие и разнородные составляющие в структуре МСК и измерительных средств. Показаны общие и отличительные функции и операции, когда элементы аппроксимации математических моделей включены непосредственно в контур МСК. Изложенный материал дает четкое определение МСК, ее отличительные особенности от известных систем технологического контроля, особенности ее исследования и пути преодоления проблем контроля свойств и процессов при работе горного или нефтегазового оборудования. Библиогр. 15, рис.2

Ключевые слова: мобильная система контроля (МСК), технологический контроль, система реального времени (СРВ), обратная связь, свойства, структурирование, аппроксимация, перестраиваемость, погрешность, многовариантность, математическая модель, противоречие.

Горные и нефтегазовые предприятия Украины имеют ряд своих существенных особенностей и специфики, связанной с безопасностью и охраной труда. Главной спецификой горной и нефтегазовой отраслей является то, что технологические процессы, машины, механизмы, оборудование потенциально опасны и допускаются в эксплуатацию (к применению) только при условии проведения экспертизы на соответствие их нормативно-правовым актам и отраслевым стандартам Украины (СОУ). Кроме того горные и нефтегазовые предприятия оснащены морально устаревшим и разнообразным оборудованием, практически находящимся на грани выработки ресурса. Однако, для полноценной интеграции в мировую экономику и выполнения международных норм по безопасности горные и нефтегазовые предприятия Украины вынуждены внедрять необходимые системы технологического контроля.

После вступления Украины в ассоциацию Европейского союза (ЕС) происходит адаптация требований и нормативно-правовых актов Украины к стандартам EC, касающихся неразрушающего контроля. Например, в 2014 г Госгорпромнадзор Украины разработал и ввел в действие новый нормативно-правовой акт НПАОП 0.00-1.63-13 «Правила сертификации специалистов по неразрушающему контролю» (утвержден приказом МЧС Украины №1387 от 10.12.2012 и зарегистрирован в Министерстве юстиции Украины № 10/225442 от 02.01.2013). Согласно НПАОП 0.00-1.63-13 неразрушающий контроль машин, механизмов, оборудования повышенной опасности имеют право осуществлять исключительно специалисты по неразрушающему

сертифицированные согласно требованиям этого акта.

Наиболее перспективными средствами технологического контроля в горной и нефтегазовой отраслях являются мобильные системы контроля (МСК) основная задача которых - оснащение потребителей, обслуживающих оборудование потенциально опасных производств, надежными компактными средствами неразрушающего контроля и мониторинга адаптированными к конкретному объекту. Разработанная МСК полностью соответствует требованиям стандартов ЕС.

Задачи МСК связаны с необходимостью проведения контрольных измерений при рабочих режимах функционирования горного или нефтегазового оборудования, при 
выполнении которых возникают проблемы, обусловленные воздействиями случайного характера и зачастую ограниченным объемом результатов экспериментальных исследований, необходимостью получения результатов обработки контроля с высокой достоверностью и принятия решений в течение минимальных сроков. МСК относится к системам реального времени (СРВ), которая собирает результаты измерений контролируемых параметров, производит их обработку в соответствии с заданными алгоритмами и выдает результат контроля за такой промежуток времени, который обеспечивает возможность решения сформулированных задач контроля. В общем виде МСК представляет собой «черный ящик», имеющий множество входов, выходов и состояний, который можно представить следующим равенством:

$$
S=f(X, Y, Z, H, G),
$$

где $S$ - оператор выходов, $X-$ входные параметры, $Y$ - выходные параметры, $Z$ параметры состояния элементов МСК, $H$ параметры состояния ее переходов, $G$ оператор переходов в МСК.

По сути, при создании МСК решается технико-экономическая задача в отыскании технического решения, обеспечивающего требуемые характеристики технологического контроля необходимых параметров на объекте при минимальных затратах. На сегодня не сформулирован единый обобщенный критерий, пригодный для всех МСК технологического контроля в горной и нефтегазовой отраслях.

Проблема МСК состоит в том, что постоянно приходится решать противоречивые требования контроля. Например, необходимо повысить точность контроля МСК на объекте, а каким образом - неизвестно. Датчики контроля МСК необходимо расположить в определенных точках технологического объекта контроля (ТОК), а эти точки недоступны или установленные датчики могут мешать функционированию ТОК и т.п.

Изложсние основного материала и результаты исследования

В МСК принимаются во внимание и учитываются следующие компоненты: цели и планы контроля, исполнители и процесс контроля, внешние и внутренние ресурсы контроля, управление и эффект контроля. Под управлением МСК понимается получение контрольной информации, ее обработку и выработку алгоритма воздействий для достижения целей контроля. Неаддитивность МСК (т.е. ее свойство, которое сводится не только к особенности составляющих его частей) позволяет обеспечивать ее целостность и создает качественно новое структурное образование по сравнению с составляющими её частями. Целостность, как закономерность, проявляется на каждом уровне иерархии МСК. Под уровнем иерархии понимается приобретение составляющими МСК частями новых качеств (свойств) при их объединении, включая наличие обратных связей, отсутствующих у него в изолированном состоянии. Отрицательные обратные связи в МСК обеспечивают стабильность и пластичность (гибкость) работы системы. Например, вычитая из входного сигнала $X$ долю выходного сигнала $Y$, делённую на коэффициент усиления, можно получить форму присутствующих нелинейных искажений. Наложив затем обратные искажения на входной сигнал $X$, можно добиться скомпенсированного сигнала [1], имеющего сниженную нелинейность.

Возникает вопрос: «Чем МСК отличается от измерительного средства»? С нашей точки зрения, МСК - это совокупность технических средств, включая измерительные преобразования, которые предназначены для сбора, сравнения, вычислительной обработки и распределения информации контроля. Энергетическим носителем информации контроля является сигнал. Под сигналом контроля понимается функционально связанная с контролируемым параметром информация. Как известно, контроль - это процесс установления соответствия между состоянием объекта контроля и заданной нормой. В отличие от измерения, при контроле МСК нет необходимости определять численное значение контролируемой величины (параметра). Однако, контроль содержит измерительные преобразования и сравнения - операции присущие измерениям, поэтому проблемы точности контроля имеют существенное значение для МСК. Таким образом, МСК - это 
совокупность измерительных

программно-управляемых преобразователей,

вычислительных и вспомогательных средств, функционирующих на основе единого метрологического обеспечения и реализующих алгоритм получения, обработки и использования информации контроля, имеющих блочно-модульный принцип исполнения, что обеспечивает гибкость, структурирование и перестраиваемость структуры МСК. Метрологическое обеспечение МСK предусматривает законодательно закрепленные процедуры нахождения оценок метрологических характеристик отдельных узлов (средств) МСК, их самопроверку на основе специальных алгоритмов и программ. Кроме того информационная и конструктивная совместимость в МСК достигается специальным интерфейсом, поэтому программное обеспечение наиболее слабое звено МСК. Чаще устройства, входящие в состав МСК, сопряжены через радиальные интерфейсы с параллельной или последовательной передачей данных самостоятельным узлам (модулям). Именно различные комбинации измерительных преобразователей, устройств и средств серийной (как правило) аппаратуры формируют возможность создавать требуемую МСК для конкретного объекта в горной и нефтегазовой отраслях.

МСК свойственны как отрицательные, так и положительные обратные связи, которые обеспечивают скачкообразное изменение свойств с появлением нового качества структурирования. Под структурированием в конфигурации МСК понимается гибкое объединение схем в общую структуру для различных начальных условий. Отрицательные обратные связи в МСК обеспечивают стабильность работы системы. Положительные обратные связи поддерживают требуемый уровень изменчивости и помогают найти (выявить) новые локализованные структуры МСК, новые и более эффективные способы контроля объекта. Особенностью МСК является то, что внутренняя структура ее элементов (измерительных преобразователей, устройств и средств) не является предметом исследования. Значение имеют только свойства, определяющие его взаимодействие с другими элементами и оказывающие влияние на характер работы МСК в целом.

МСК является эргатической системой (часть функций выполняется оператором) так как при ее контроле в ряде случаев необходимо принимать решение на основе неполной информации и учитывать не формализуемые факторы. На рис. 1 показан принцип сбора контрольной информации МСК с участием оператора.

МСК характеризуется некоторым набором параметров (в конкретной зависимости от объекта контроля и требования необходимой точности) и закономерностями, которые определяются на основе исследований не всего объекта контроля, а только некоторой его части с помощью некоторых правил выборки компонентов, характеризующих объект или процесс контроля. На основании исследований этой части объекта контроля выборочные характеристики распространяют на весь объект контроля (при этом делаются соответствующие оговорки). В этом примере показан вариант возникновения административного противоречия в МСК, возникающего между потребностью контроля и возможностью её удовлетворить.

Борьба с противоречиями в МСК, как известно, ведется двумя методами. Конструкторский путь, когда стараются проектировать МСК таким образом, чтобы найти компромиссное решение (немного выиграл в одном параметре, при этом поступился в другом) которое вписывается в техническое задание на контроль МСК. Практика свидетельствует, что успех конструкторского пути не всегда достигается, а на объекте внедряется та МСК, у которой улучшение одного показателя (параметра) МСК не приводит к существенному ухудшению другого. Как показывает опыт, такие МСК, быстро устаревают, требуют модернизации или замены.

Второй путь - разработка новой совершенной МСК. Выдающийся авиаконструктор Роберто ди Братини [2,5,6] при решении противоречий требовал определять факторы, играющие решающую роль, отделив все второстепенные элементы. «После этого надо сформулировать наиболее контрастное противоречие: или - или.... Решение задачи 
надо искать в логической композиции тождества противоречий.... и - и». Ориентация на устранение и обострение противоречий сделала Роберто ди Братини ярким генератором идей для авиации с довоенного периода по настоящее время [2-6]. Вопрос «Быть или не быть?» в изобретательской постановке должен звучать так: «И быть и не быть!». Убедительный опыт Роберто ди Братини, его последователей и личный опыт автора показывает, что противоречий не надо бояться, их надо преодолевать по принципу и - и. Противоречия необходимо разрешать. Автор убежден, что эффективную МСК можно создать только тогда, когда противоречия преодолеваются, а не принято компромиссное решение по их преодолению. Например, интегральный акселерометр ADXL105 с диапазоном $50 \mathrm{~g}$ (где $g$ - единица ускорения свободного падения) имеет по паспорту типичное значение спектральной плотности шума $1 \mathrm{mg} /$ Цц в полосе 10-1000 Гц. На базе ADXL105 для МСК типа «МАК-3» был создан датчик ДВ-1 (для замены МП-95) Рис 2.

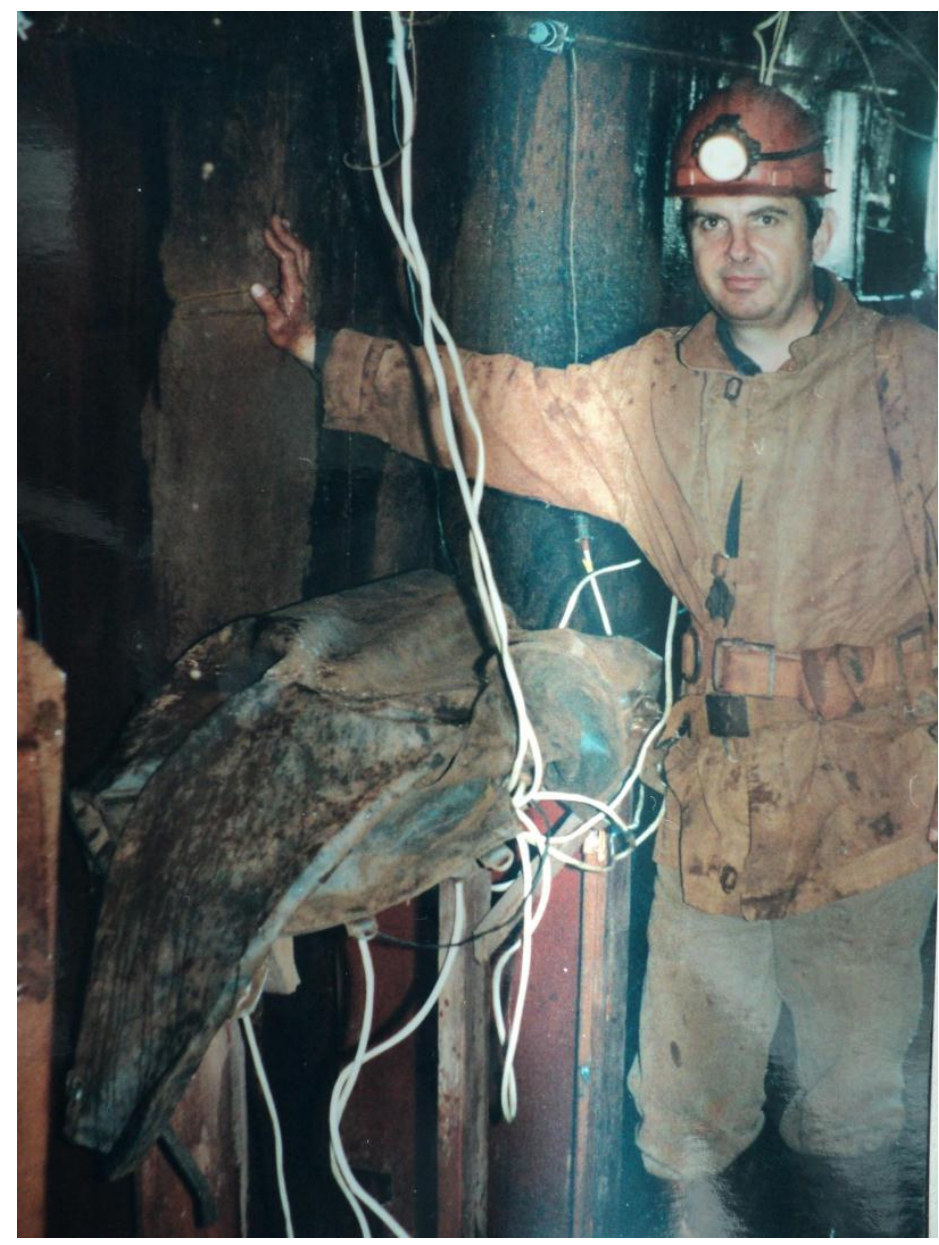

Рисунок 1 - Апробация нового способа контроля МСК на шахтах «Родина» и «Северная вспомогательная» (г. Кривой Рог) ОАО Кривбассжелезрудком 


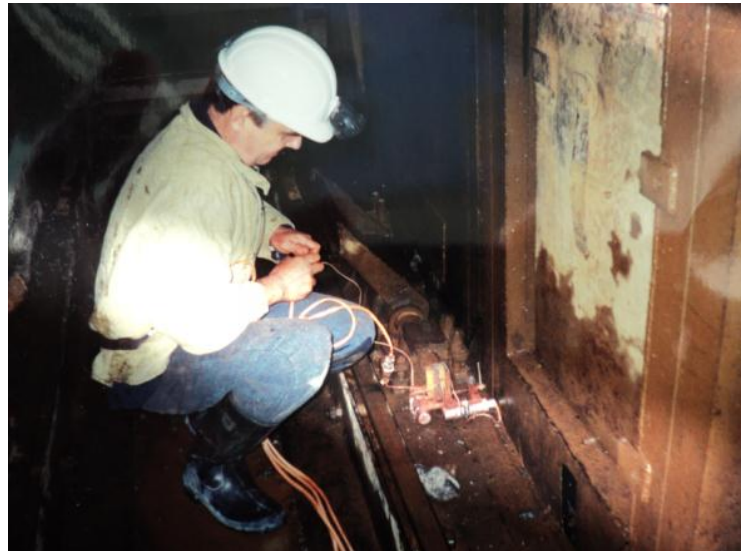

Рисунок 2 - Шахтный эксперимент для сравнения экспериментального датчика ДВ-1 с МП-95 (мобильная система контроля типа «МАК-3»)

Однако датчик ДВ-1 в отличие от МП-95 непривычно искажал сигнал контроля в МСК. Для облегчения программы обработки в МСК типа «МАК-3» принято компромиссное решение - включить фильтр низкой частоты (ФНЧ). Используемый в акселерометре ДВ-1 "МАК-3" ФНЧ имеет частоту среза 100 Гц (как выполнено в ДВ-1 "МАК-3"), действующее значение шума на выходе фильтра составило 10 $\mathrm{mg}$, а амплитудное, с вероятностью 0,997 - в пределах $30 \mathrm{mg}$. Поскольку вся шкала датчика ДВ-1 составляет 50 g, то динамический диапазон его стал равен 64,4 дБ [7]. Из приведенного примера понятным является существенное ухудшение характеристик датчика, особенно в начале диапазона измерения.

Сформулировать технические требования (технические условия) для МСК - значит уточнить исходную проблемную ситуацию на объекте контроля (в горной выработке или нефтегазовом промысле), определив цель, ограничения и критерии выбора решения. Все перечисленные факторы (категории) определяют желаемое состояние объекта контроля и его потребности, к которым необходимо прийти в результате реализации МСК.

Ограничения МСК обусловлены условиями, при которых достижения цели можно считать приемлемым для данного контроля. Запреты, в основном, сформулированы в нормативноправовых актах Украины и отраслевыми стандартами Украины (СОУ) $[7,8]$ и имеют вид запретов на изменения или применение чеголибо или, наоборот, указаний на необходимость применения какого-либо определенного средства для достижения цели контроля. К ограничениям МСК относятся: указания на допустимые пределы затратных ресурсов и на количественные характеристики, не отраженные в формулировке цели. Критерии выбора решения в МСК отражают только наиболее существенные признаки или их совокупность.

Получение информации об объекте контроля путем построения математических моделей по результатам контроля является целью МСК. Такие модели являются аппроксимирующей формой контролируемого МСК объекта, т.е. моделью его реального состояния на момент контроля. Особенностью МСК является то, что предполагается включение этих аппроксимирующих математических моделей непосредственно в рабочий контур МСК $[7,8]$. Необходимо считать, что использование предлагаемого аппроксимационного подхода, как общей платформы для построения методического, математического и алгоритмического обеспечения МСК, дает предпосылки системного объединения априорной информации через математическую модель, отражающей физическую сущность решаемой задачи контроля, структуры и характеристик средств и методов контроля, а также процедуры осуществления и интерпретации результатов контроля. Под аппроксимационным подходом понимается некоторое обобщение принципов, методов, способов и средств в МСК, направленных на построение аналитических моделей, вид которых выбирается на основе априорной информации и имеющейся фактической (экспериментальной) информации с учетом целей проводимого исследования на объекте контроля $[7,8]$.

Специфическим свойством предлагаемого аппроксимационного подхода является многовариантность порождаемых им методов и средств реализации МСК, которая следует из многовариантности интерпретаций любых данных контроля, в которых имеет место случайность и неопределенность. Автор считает, что поскольку любая аппроксимация дает приближенный результат, в условиях многовариантности нет смысла искать 
наилучшие решения в отношении выбора моделей и методов их параметрического синтеза. Выбор вариантов решения задачи в МСК следует осуществлять по принципу непротиворечивости результата, целям и задачам конкретного контроля. Например, при проведении измерения физической величины, цели и критерии предельно ясны - получить как можно более точный результат простыми средствами измерения за кратчайшее время. А в рассматриваемом случае исходные предпосылки, методы и средства достижения результата в МСК, должны быть согласованы и с исходными данными - случайными, часто недостоверными, с априорной информацией, и с достигаемыми целями контроля. В МСК особенную роль играет априорная информация при решении обратных задач. С решением таких задач связаны процедуры коррекции результатов контроля, направленные на устранение влияния аппаратной составляющей МСК (редукция к идеальному прибору) разделение эффектов от влияния отдельных факторов, а также процедуры интерпретации результатов контроля.

В МСК способ определения характеристик сигналов основан на обработке результатов контрольных измерений некоторого количества их мгновенных значений. Под сигналом контроля понимается выражение некоторой математической функции, однозначно отображающей изменения во времени контролируемого МСK технологического параметра. Способ имеет обобщение в рамках метода аппроксимации, обеспечивающего равенство значений некоторого сигнала и его модели $x_{N}\left(t, \alpha_{1}, \cdots, \alpha_{n}\right)$ в выбранных точках времени $t$.

При различных произвольных значениях аргумента $t$ проводятся контрольные измерения $n$ значений сигнала, и составляется система $n$ уравнений:

$$
x_{N}\left(t, \alpha_{1}, \cdots, \alpha_{n}\right)=x\left(t_{i}\right), i=1, \cdots, n,
$$

где $\alpha_{n}$ - контрольные параметры.

Система уравнений (1) решается относительно параметров $\alpha_{1}, \cdots, \alpha_{n}$. Основной проблемой внедрения этого метода являться анализ точности и обоснование достоверности результатов контроля, поскольку в основу построения метода не включено ни одного метрологического критерия. Однако при совпадении модели и сигнала получается методически точный результат. Допускается, что при выборе модели без должного обоснования и несоответствии ее виду моделируемого сигнала оценки контрольных параметров могут существенно отличаться от оптимальных в равномерном или среднеквадратическом смыслах. Поэтому каждое конкретное приложение должно сопровождаться тщательным метрологическим анализом.

В МСК качество решения аппроксимации оценивается результирующей погрешностью измерения, включающей в себя все составляющие, определяющие несоответствие модели и моделируемой зависимости [7]. При случайных сигналах используются среднеквадратические интегральные оценки. При детерминированных сигналах при необходимости могут быть получены более жесткие оценки равномерного приближения.

Для получения аналитических оценок погрешностей в $\mathrm{MCK}$ предлагается использовать следующие модели общего вида. В качестве эталонов могут служить функциональные ряды

$$
x_{\text {эталон }}(t)=\sum_{i=0}^{M} \alpha_{i} \psi_{i}(t), M \rightarrow \infty,
$$

где $\alpha_{i}$ - контрольные параметры.

В качестве метрологического критерия в МСК предлагается использовать минимум взвешенной среднеквадратической погрешности аппроксимации анализируемой функции $R(v)$ ее моделью $R_{n}(v, \vec{\alpha})$

$$
\min \left\{\varphi\left(R, R_{N}\right)=\int_{d}^{c}\left[R(v)-R_{n}(v, \vec{\alpha})\right]^{2} \chi(v, \vec{\beta}) d v\right\},
$$

где $\chi(v, \vec{\beta}) \geq 0$ - весовая функция с параметрами $\vec{\beta}=\beta_{1}, \beta_{2}, \cdots$.

Достоинство критерия (3) заключается в возможности выделения участков наиболее точного приближения и позволяет косвенно решить ряд частных задач анализа. Подобный критерий был использован в работах [9-13]. В случае необходимости оценивания в МСК характеристик, функционально связанных с 
параметрами $\vec{\alpha}, \quad$ формулируется задача рационального выбора весовой функции $\chi(v, \vec{\beta})$ и подстройки её параметров $\vec{\beta}$.

Таким образом, следует считать, что алгоритмизация процессов создания моделей МСК может дальше развиваться в предложенном направлении. Обоснованная интерпретация результатов контроля МСK должна базироваться на априорной информации, формализованной в виде априорной модели объекта контроля и апостериорной информации, полученной путем обработки результатов контроля МСК. Априорная информация может быть также учтена при синтезе алгоритмов обработки данных контроля и оказать существенное влияние на структуру и свойства МСК. Модель МСК при формулировке задачи контроля формируется на уровне экономики и, отчасти, техники, а поиск ведется на физическом уровне контроля и лишь, затем от техникоэкономической модели переходят к практической постановке задачи. Критерий выбора МСК отражает наиболее желаемое решение, которое обеспечивает достижение цели контроля при заданных ограничениях среди множества возможных решений. Критериями в МСК, как правило, являются: цена, точность, габариты, простота обслуживания и т.п. По этим критериям проводится оптимизация МСК. Считается, что правильный выбор критериев по существу эквивалентен правильной формулировке задачи. Однако, в большинстве случаев это дает более существенный результат, чем формулировка задачи, и в том числе выбор правильной точки зрения и правильной области допустимых решений [14]. Проведя анализ объекта контроля, можно определить все требуемые характеристики и параметры контроля для МСК на любом уровне. В том числе совокупность целей контроля, которые могут быть достигнуты на объекте с помощью МСК. Затем намечается несколько вариантов МСК, далее с помощью анализа определяются характеристики этих вариантов на требуемом уровне контроля, а затем путем сравнения выявленных характеристик с моделью решения производится отсев всех непригодных вариантов. Автором на основе практического опыта разработан итерационный (последовательный) метод приближений, когда каждый МСК уточняет предыдущую версию, приближаясь к требуемому варианту.

\section{Bblводы}

Рассмотрены основные составляющие структуры МСК и измерительных средств, обосновано их различие, показаны общие и отличительные функции (операции). Выделены и проанализированы противоречия объединения структуры мобильной системы контроля (МСК) посредством математического моделирования априорной информации. Показано, что основной проблемой является анализ точности и обоснование достоверности результатов контроля МСК. Приведены преимущества и недостатки конструкторского и изобретательского пути создания МСК. Для получения аналитических оценок погрешностей в МСК предложено использовать в качестве эталонов модели общего вида, а в качестве метрологического критерия использовать минимум взвешенной среднеквадратической погрешности. Предложен аппроксимационный подход выбора вариантов решения задачи в МСК по принципу непротиворечивости результата контроля.

Таким образом, МСК - это совокупность программно-управляемых измерительных преобразователей, вычислительных и вспомогательных средств, функционирующих на основе единого метрологического обеспечения, у которого аппроксимирующие математические модели включены непосредственно в рабочий контур.

1.Лопатін В. В., Дослідження експериментальної мобільної системи контролю вібрації свердловинної итангової насосної установки/ В.В. Лопатін// Методи та прилади контролю якості. Науково-технічний журнал - Івано-Франківськ .- №1(30), 2013, С. 815.

2. Чутко И. Красные самолёты/ Чутко И. // Мост через время: сб. - М.: Политиздат, 1989. - 333 c.

3.ди Бартини Р.О., Множественность геометрий и множественность физик. /Р. О. ди Бартини, П. Г. Кузнеияов // Моделирование динамических систем. Теоретические вопросы моделирования. вып. 2. Труды семинара 
«Кибернетика электроэнергетических систем». Брянск. 1974. http://www.situation.ru/app/rs/lib/pobisk/ur_model _sys/ur_model_sys.htm

4.P. O. $о$ О Бартини «Некоторые соотношения между физическими константами». Доклады Академии наук том 163, № 4, - 1965, С. 861-864.

5. Бартини, человек из будущего... [Электронный ресурс]. - Режим docmyna:http://www.zrd.spb.ru/news/2013-

01/news-0275.htm html. - Загл. с экрана.

6. Бартини Роберт Людвигович - один из малоизвестных героев советской авиаконструкторской школь [Электронный ресурс]. - Режим доступа:

https://topwar.ru/14378-bartini-robertlyudvigovich-odin-iz-maloizvestnyh-geroevsovetskoy-aviakonstruktorskoy-shkoly.html html. Загл. с экрана.

7.Лопатін В.В., Наукові основи розроблення системи контролю технічного стану жсорсткого армування шахтних стовбурів. Автореферат дис. доктора техн. наук: 05.11.13./ Лопатін В. В. - ІваноФранківськ 2013. - 34c.

8. Лопатин В. В., Обеспечение необходимой точности мобильных систем контроля в горной $u$ нефтегазовой отраслях/ Лопатин В. В.// Методи та прилади контролю якості. Науковотехнічний журнал - Івано - Франківськ - № 2 (37), 2016, C. 5-13

9. Батищев В.И., Аппроксимационные методы $и$ технологии для построения информационно-измерительных систем промышленного контроля, испьтаний $u$ диагностики. Автореферат дис. доктора техн. наук:05.11.16./ Батищев В.И.- Самара 2003.$34 c$.

10. Мешеряков В.А., Основы методики расследования преступлений в сфере компьютерной информации. Автореферат дис. доктора юр. наук:12.00.09./ Мещчеряков В.А. Воронеж 2001. -39с.

11. Батищев В.И., Измерительномоделируюшие методы оцуенивания функциональных хараткеристик случайных прочессов // Проблемь управления $u$ моделирования в сложных системах: Труды IV международной конференции (Самара, 17-23 июня 2002 2.). - Самара: СНЦ РАН, 2002. С. 524-530.

12. Батищев В.И., Аппроксимачионные методы и системы промышленных измерений, контроля, испытаний, диагностики./ В.И. Батищев, В.С. Мелентьев // М.: Машиностроение - 1. 2007-393 с.

13. Мелентьев В.С., Аппроксимационные методы и средства измерения параметров двухполюсных электрических цеепей/ В.С. Мелентьев, В.И. Батищев // М.: Физматлит, $2012-200 c$.

14. Goode, Harry H., Robert E. Machol. System Engineering: An Introduction to the Design of Large-scale Systems [Электронный ресурс]. Режим доступа:

https://searchworks.stanford.edu/view/131402 6 html. -Загл. с экрана.

Поступила в редакцію 10.11.2018 р. Рекомендували до друку: докт.техн.наук, проф. Райтер П. М., докт. техн. наук, проф. Олійник А.П. 